\title{
Awareness level of family planning methods in adolescent girls of different socio-economic groups in rural sectors, in central India
}

\author{
Anuradha Kakani*, Arpita Jaiswal
}

Department of Obstetrics \& Gynecology, AVBRH, Sawangi, Wardha, Maharashtra, India

Received: 15 November 2012

Accepted: 11 December 2012

*Correspondence:

Dr. Anuradha Kakani,

E-mail: anuradhakakani@gmail.com

\begin{abstract}
Background: Adolescence, the transition from childhood to adulthood is an important crossroad. Studies are available which suggest that a considerable number of adolescent boys (16 to 14\%) and girls (1 to 10\%) engage in premarital sexual activity. All though importance of health education and health counseling for adolescents have been incorporated in the formal education system but there are no large scale community based studies to assess awareness level of adolescent girls about the method of family planning. The present study was undertaken to evaluate the effect of socio-economic factor on the awareness level of adolescent girls with special reference to the methods of family planning, and their concepts about long term effects of high population growth.

Methods: The study samples were higher secondary girl students between 15 to 19 years of age in 5 rural schools (Hindi \& English medium) of Wardha district, Maharashtra, India. The survey programme was conducted during a period of one year from July 2011 to June 2012. A questionnaire was prepared in local language.

Results: The education level of parent in upper-middle (group A) was significantly more than low-economic group (group B). Knowledge about hormonal contraceptive pill in group A was significantly high than group B and the idea about surgical technique and condom was also high in group A than group B. Regarding emergency contraceptive technique, the idea in group A was high but in group B, the rate was very low.

Conclusions: The awareness programme should be conducted in formal education in the school curricula so that adolescent girl's knowledge, attitude and practice can be assessed.
\end{abstract}

Keywords: Adolescent, Methods of family planning

\section{INTRODUCTION}

Adolescence, the second decade of life, the transition from childhood to adulthood is an important crossroad. Today, approximately one-fifth of the world's population is that of adolescents (10-19 years of age), 85 percent of them in developing countries. ${ }^{1}$ There are an estimated 200 million adolescents in India, comprising over one-fifth of the entire population. ${ }^{2}$

Studies are available which suggest that despite the general censure of premarital sex, a considerable number of adolescent boys (16 to $14 \%$ ) and girls (1 to $10 \%$ ) engage in premarital sexual activity. However various knowledge, attitude and practice studies bring out disturbingly low level of contraceptive awareness among adolescents. About 10 to 15 percent of total births in the world (about 12 to 18 million a year) take place among teenage mothers. ${ }^{3}$ The UN demographic data indicates that in many of the developing and industrialized countries, births to women fewer than twenty years of age represent a growing proportion of all births. Adolescent abortions are estimated to be up to 4.4 million per year, most of which are unsafe because of being performed illegally and under hazardous circumstances by quacks. ${ }^{3}$

Although importance of health education and health counseling for adolescents have been incorporated in the formal education system but there are no large scale community based studies to assess awareness level of adolescent girls about the method of family planning. In India problems are more difficult and complicated because of marked socio-economic diversity as mentioned by Gupta and Sinha. ${ }^{4}$ Unfortunately, young 
women's bodies are maturing earlier these days, and to add to this the young women are tempted to experience sexual intercourse at an earlier age. So if a region is experiencing a net population growth rate (even $1 \%$ doubles in 70 years), or if it is already exceeding carrying capacity, it is important for sex education, family planning, and self-esteem programmes to be concentrated on young women in their teen years.

The present study was undertaken to evaluate the effect of socio-economic factor on the awareness level of adolescent girls with special reference to the methods of family planning, and their concepts about long term effects of high population growth. The aims and objectives of this study are therefore to find out in rural sector the awareness about the family planning practices in adolescent girls of different socioeconomic groups and to assess their knowledge about long term effect of high population growth on future generation.

\section{METHODS}

The study samples were higher secondary girl students between 15 to 19 years of age in 5 rural schools (Hindi \& English medium) of Wardha district, Maharashtra, India. The survey programme was conducted during a period of one year from July 2011 to June 2012. A questionnaire was prepared in local language. The questionnaire was first explained to the school girls and then they were asked to fill it carefully having questions mainly on following topics.

(a) Education level of father and mother.

(b) Economic level of family.

(c) Name of the different family planning methods they know.

(d) Source of information about those methods.

Attitude of adolescent girls towards population problems was monitored. For these purposes following questions were studied. (a) Whether our nation is facing a serious problem of overpopulation?

(b) Whether it should be reduced without delay?

(c) Whether increased population will cause any problem to the happiness of the people in the country?

(d) Is there any responsibility of yours to solve this problem?

The awareness level of adolescent girls in this field with the socio-economic status was assessed.

A total of 850 girls of age group 15-19 years were enrolled in the study out of which only 600 responded, rest of the girls i.e. 250 did not give their response in the questionnaire sheet may be due to their lack of interest in such type of programme or they were too shy to respond, or were engaged in other events of school. The target population was then divided into two groups.

Group A: Three hundred and forty girls belonged to high and upper middle socio-economic status (having monthly per capita family income more than Rs. 3000/-).

Group B: Two hundred and sixty girls belonged to low socio-economic status (having monthly per capita family income less than Rs. 3000/).

The outcome data were analyzed systematically by applying chi-square test.

\section{RESULTS}

The education level of parents in upper-middle (group A) was significantly more than low-economic group (group B). In group A $30.29 \%$ parents were graduates while in group B only $12.3 \%$ were graduates. In contrast, educational level below primary school in group A was $10.58 \%$ and in group B it was $39.61 \%$ (Table 1).

Table 1: Education level of father and mother.

\begin{tabular}{|c|c|c|c|c|c|c|c|c|}
\hline \multirow[t]{2}{*}{ Group } & \multicolumn{2}{|c|}{$\begin{array}{c}\text { Only one/both Parents } \\
\text { Graduate }\end{array}$} & \multicolumn{2}{|c|}{$\begin{array}{l}\text { Only one/both } \\
\text { Parents Higher } \\
\text { Secondary school }\end{array}$} & \multicolumn{2}{|c|}{$\begin{array}{c}\text { Only one/both } \\
\text { Parents Secondary } \\
\text { school }\end{array}$} & \multicolumn{2}{|c|}{$\begin{array}{l}\text { Only one/both } \\
\text { Parents Primary } \\
\text { school }\end{array}$} \\
\hline & No. & $\%$ & No. & $\%$ & No. & $\%$ & No. & $\%$ \\
\hline$\underset{(n=\mathbf{3 4 0})}{\mathbf{A}}$ & 103 & 30.29 & 125 & 36.76 & 76 & 22.35 & 36 & 10.58 \\
\hline $\begin{array}{c}\text { B } \\
(n=260)\end{array}$ & 32 & 12.3 & 47 & 18.07 & 78 & 30 & 103 & 39.61 \\
\hline$\aleph 2$-value & \multicolumn{8}{|c|}{32.00} \\
\hline$p$-value & \multicolumn{8}{|c|}{$p<0.0001$, Highly significant } \\
\hline
\end{tabular}


Table 2: Awareness level of different method of family planning.

\begin{tabular}{|c|c|c|c|c|c|c|c|c|c|c|}
\hline \multirow[t]{2}{*}{ Group } & \multicolumn{2}{|c|}{$\begin{array}{c}\text { Safe/Danger } \\
\text { period }\end{array}$} & \multicolumn{2}{|c|}{ Condom } & \multicolumn{2}{|c|}{ Oral pills } & \multicolumn{2}{|c|}{$\begin{array}{l}\text { Permanent } \\
\text { contraception }\end{array}$} & \multicolumn{2}{|c|}{$\begin{array}{c}\text { Emergency } \\
\text { contraception }\end{array}$} \\
\hline & No. & $\%$ & No. & $\%$ & No. & $\%$ & No. & $\%$ & No. & $\%$ \\
\hline$\underset{(n=340)}{\mathrm{A}}$ & 207 & 60.88 & 210 & 61.76 & 103 & 30.29 & 78 & 22.94 & 30 & 8.8 \\
\hline $\begin{array}{c}\text { B } \\
(n=260)\end{array}$ & 69 & 26.53 & 91 & 35 & 53 & 20.38 & 25 & 9.61 & 6 & 2.3 \\
\hline \$2-value & \multicolumn{10}{|c|}{3.22} \\
\hline$p$-value & \multicolumn{10}{|c|}{$0.52, \mathrm{NS}, p>0.05$} \\
\hline
\end{tabular}

Table 3: Sources of information about the method of family planning programme.

\begin{tabular}{|c|c|c|c|c|c|c|c|c|}
\hline \multirow{2}{*}{ Group } & \multicolumn{2}{|c|}{ None } & \multicolumn{2}{|c|}{ Friends/ Relatives } & \multicolumn{2}{|c|}{ Books/Multimedia } & \multicolumn{2}{|c|}{ Teacher } \\
\hline & No. & $\%$ & No. & $\%$ & No. & $\%$ & No. & $\%$ \\
\hline$\underset{(n=340)}{\mathbf{A}}$ & 30 & 8.82 & 82 & 24.11 & 130 & 38.23 & 98 & 28.82 \\
\hline B $(n=260)$ & 76 & 29.23 & 82 & 31.53 & 88 & 33.84 & 14 & 5.38 \\
\hline$\aleph 2$-value & \multicolumn{8}{|c|}{19.80} \\
\hline$p$-value & \multicolumn{8}{|c|}{0.0002, Significant, $p<0.05$} \\
\hline
\end{tabular}

Table 4: Awareness of facts about over population and attitude of adolescent towards population problem.

\begin{tabular}{|c|c|c|c|c|c|c|}
\hline & \multicolumn{4}{|c|}{ Awareness (229) (38.16) } & \multirow{3}{*}{$\aleph 2$-value } & \multirow{3}{*}{$p$-value } \\
\hline & \multicolumn{2}{|c|}{$\begin{array}{c}\text { Group A } \\
(n=154)(67.24)\end{array}$} & \multicolumn{2}{|c|}{$\begin{array}{c}\text { Group B } \\
\text { (75) }(32.75)\end{array}$} & & \\
\hline & No. & $\%$ & No. & $\%$ & & \\
\hline Need to control population & 136 & 88.3 & 58 & 77.33 & 4.19 & $\begin{array}{c}0.04 \\
\mathrm{~S}, p<0.05\end{array}$ \\
\hline $\begin{array}{l}\text { Negative impact of over population on } \\
\text { our happiness }\end{array}$ & 102 & 66.23 & 47 & 62.66 & 0.19 & $\begin{array}{l}0.65, \mathrm{NS} \\
p>0.05\end{array}$ \\
\hline Responsibility to control over population & 78 & 50.64 & 35 & 46.66 & 0.32 & $\begin{array}{l}0.57, \mathrm{NS} \\
p>0.05\end{array}$ \\
\hline $\begin{array}{c}\text { Impact on resources due to over } \\
\text { population }\end{array}$ & 70 & 45.45 & 30 & 40 & 0.51 & $\begin{array}{l}0.47, \mathrm{NS} \\
p>0.05\end{array}$ \\
\hline $\begin{array}{c}\text { Coming generation will face problem of } \\
\text { population explosion }\end{array}$ & 65 & 42.20 & 25 & 33.33 & 1.72 & $\begin{array}{c}0.18 \\
\mathrm{NS}, p>0.05\end{array}$ \\
\hline
\end{tabular}

Knowledge about hormonal contraceptive pill in group A was significantly high than group $\mathrm{B}$ and the idea about surgical technique and condom was also high in group $\mathrm{A}$ than group B (Table 2).

Table 3 shows that teachers play a vital role for awareness about methods of family planning in group A but mother, relatives and friends play a key role in group B.
$38.16 \%$ of adolescents were aware about over population. The levels of unawareness significantly differ between the two groups and it was very low in group B (Table 4).

\section{DISCUSSION}

Reproductive health of adolescent girls have been neglected since long, but in last 10-12 years an emphasis has been given to raise their awareness level by introduction of lifestyle education in school curriculum. ${ }^{5}$ 
It has been found that education level of parent in uppermiddle (group A) was significantly more than loweconomic group (group B). In group A 30.29\% parents were graduates while in group B only $12.3 \%$ were graduates. In contrast, educational level below primary school in group A was $10.58 \%$ and in group B it was $39.61 \%$ (Table 1 ).

Regarding the awareness level about the different methods of family planning, a significant difference was noted between the two groups which were also supported by Beekle and McCabe. ${ }^{6}$ We have noted that knowledge about hormonal contraceptive pill in group A was significantly high than group $\mathrm{B}$ and the idea about surgical technique and condom was also high in group A than group B (Table 2). Regarding emergency contraceptive technique, the idea in group $\mathrm{A}$ was high but in group B, the rate was very low. This variation was not only due to the educational level status but also due to the socioeconomic status as reported by Gage. ${ }^{7}$

Mass media like TV, Radio and Periodicals play a vital role to raise the awareness in this field and there was no significant difference between the two groups. The role of mass media to raise awareness level in adolescent was supported by Watsa. ${ }^{8}$ In contrast, teachers play a vital role for such awareness in group A but mother, relatives and friends play a key role in group B (Table 3 ). This is also due to variation in socio-economic status of the family as in group A, the parents' restriction for adolescent girls is very high that resist their free discussion with their friends, which is not applicable for group B as per the observation of Beekle and McCabe. ${ }^{6}$

Some questions were framed to know the attitude of the adolescent girls of both groups about the national problems that may be developed due to uncontrolled family size. It was seen that out of 600 adolescents who participated in the study only $38.16 \%$ of adolescents were aware about over population. It was seen that the levels of unawareness significantly differ between the two groups and it was very low in group B (Table 4). The socio-economic factors play a key role in this purpose that has been supported by Aggarwal et al. ${ }^{9}$ Lack of adequate knowledge in family planning methods and the poor attitude and practices about negative side of over population in adolescent girls may result in early pregnancy and sexual disharmony as observed by Gupta. $^{10}$

The awareness programme should be conducted in formal education in the school curricula and counseling should be done for value moral education in life. Working on something at a grass root level ultimately adds to the economy and development of the country especially in India where the transition of developing country to developed country will occur only if we focus the betterment of the rural population.

\section{REFERENCES}

1. Saipre KE. Contribution to obstetrics and gynecology, Pearson Professional. Singapore 1996;47:2.

2. Guria M, De D, Bera TK, Ghosh D. Awareness Level of Family Planning Practices in School Going Adolescent Girls of Different Socio-economic Groups in Rural Sectors, West Bengal. J Hum Ecol 2009;27:101-4.

3. Gandhi AB. Reproductive health of adolescent girl. J Obstet Gynaecol India 1999;49:132-5.

4. Gupta S, Sinha A. Awareness about reproduction and adolescent changes among school girls of different socioeconomic status. J Obstet Gynaecol India 2006;56:324-8.

5. Munthali A et al. Adolescent Sexual and Reproductive Health in Malawi: Results from the 2004 National Survey of Adolescents, Occasional Report, New York: Guttmacher Institute, 2006, No. 24.

6. Beekle AT, McCabe C. Awareness and determinants of family planning practice in Jimma, Ethiopia. Int Nurs Rev 2006;53:269-76.

7. Gage AJ. Women socioeconomic position and contraceptive behavior in Togo. Stud Fam Plann 1995;26:264-77.

8. Wasta MC. Young Sexuality. Mumbai (SECERT). Family Planning Association of India 1994.

9. Aggarwal H, Vaid S, Vaid N. Comparison of the level of awareness of family planning measure in the urban and urban-slum women. Anthropol 2005; 7:35-40.

10. Gupta M. Sexuality in the Indian subcontinent. Sex Marital Ther 1994;9:57-69.

DOI: $10.5455 / 2320-1770$. ijrcog000312

Cite this article as: Kakani A, Jaiswal A. Awareness level of family planning methods in adolescent girls of different socio-economic groups in rural sectors, in central India. Int J Reprod Contracept Obstet Gynecol 2012;1:3-6. 